Int. J. Electrochem. Sci., 11 (2016) $5877-5890$

\title{
Corrosion Behavior of Two cp Titanium Dental Implants Connected by Cobalt Chromium Metal Superstructure in Artificial Saliva and the Influence of Immersion Time
}

\author{
Ala'a AlOtaibi $^{1,2}$, El-Sayed M. Sherif ${ }^{1,3,4}$, Spiros Zinelis ${ }^{5,1}$, Youssef S. Al Jabbari ${ }^{1,2, *}$ \\ ${ }^{1}$ Dental Biomaterials Research and Development Chair, College of Dentistry, King Saud University \\ ${ }^{2}$ Department of Prosthetic Dental Science, College of Dentistry, King Saud University, P.O. Box: \\ 60169, Riyadh 11545, Saudi Arabia \\ ${ }^{3}$ Center of Excellence for Research in Engineering Materials (CEREM), Advanced Manufacturing \\ Institute (AMI), King Saud University, P.O. Box: 800, Riyadh 11423, Saudi Arabia \\ ${ }^{4}$ Electrochemistry and Corrosion Laboratory, Department of Physical Chemistry, National Research \\ Centre (NRC), Dokki, 12622 Cairo, Egypt \\ ${ }^{5}$ Department of Biomaterials, School of Dentistry, National and Kapodistrian University of Athens, \\ Athens, Greece. \\ *E-mail: yaljabbari@ksu.edu.sa
}

doi: $10.20964 / 2016.07 .77$

Received: 21 March 2016 / Accepted: 17 May 2016 / Published: 4 June 2016

In this study, we invistegate the effect of connecting two similar cp titanium implant fixtures and the immersion time on the electrochemical behavior of these implant fixture system using Straumann ${ }^{\circledR}$ (Institute Straumann, Basel, Switzerland) coupled with cobalt chrome framework in artificial saliva. The two implant fixtures had the same composition, diameter, length and surface treatment. The corrosion measurements were carried out using open-circuit potential, cyclic potentiodynamic polarization, electrochemical impedance spectroscopy, and chronoamperometric current-time measurements. The surface morphology and the elements analysis for the corroded samples were investigated using scanning electron microscope and energy dispersive X-ray analyzer. The effect of prolonging the period of immersion time on the corrosion of the couple in the saliva from 1 to 24 and further to $48 \mathrm{~h}$ before measurements was also reported. It has been found that the tested implant system has high passivation against corrosion and the intensity of its uniform corrosion increases with increasing the immersion time in the artificial saliva from 1 to 24 and further to $48 \mathrm{~h}$. This was confirmed by the remarkable increase in the values of corrosion current and the decrease in the polarization resistance values over time. On the other hand, the severity of pitting corrosion was noticed to decrease with time, which was indicated via decreasing the area of hysteresis loop and shifting the values of the protection potential to more positive direction. 
Keywords: corrosion, dental implant systems, EIS, polarization, Straumann ${ }^{\circledR}$, titanium alloys

\section{FULL TEXT}

(C) 2016 The Authors. Published by ESG (www.electrochemsci.org). This article is an open access article distributed under the terms and conditions of the Creative Commons Attribution license (http://creativecommons.org/licenses/by/4.0/). 